\title{
General Burden of Adult Atopic Dermatitis: An Observational Study of Disease Perceptions among Patients and Dermatologists in France
}

Angèle SORIA ${ }^{1}$, Claire THÉNIÉ2 ${ }^{2}$ Christina BIENENFELD ${ }^{3}$ and Delphine STAUMONT-SALLÉ 4

${ }^{1}$ Department of Dermatology and Allergology, Assistance Publique - Hôpitaux de Paris (APHP), University of Sorbonne, Tenon Hospital APHP, Paris, ${ }^{2}$ Sanofi Medical, ${ }^{3}$ Institut français d'opinion publique and ${ }^{4}$ Department of Dermatology, Centre Hospitalier Universitaire, Lille, University of Lille, INFINITE U1286 Inserm, Lille, France

It is important to understand patients' and dermatologists' perceptions of various aspects of atopic dermatitis, but there is a lack of studies on quality of life and stakeholder viewpoints in this therapy area. The aim of this study was to compare patients' and dermatologists' viewpoints regarding the impact of atopic dermatitis that is uncontrolled by topical corticosteroids. Data were collected from 348 adult patients who responded to self-administered questionnaires, and 150 telephone interviews with the dermatologists who selected them. Patients and dermatologists reported both convergent and divergent assessments of the impact of atopic dermatitis and its treatment. Notable areas of agreement were regarding the safety of emollients, the time required and difficulty of applying topical corticosteroids, especially to certain parts of the body. Divergent views involved the perceived efficacy of available treatments and the impact of atopic dermatitis on professional life. A greater understanding of these differences would help dermatologists to optimize patient care.

Key words: atopic dermatitis; topical corticosteroids; dermatologist; patient assessment; disease impact.

Accepted Oct 26, 2021; Epub ahead of print Aug 26, 2021

Acta Derm Venereol 2021; 101: adv00588.

Corr: Delphine Staumont-Sallé, Department of Dermatology, Claude Huriez Hospital - Regional University Hospital Center, FR-59037 Lille Cedex, France. E-mail: Delphine.salle@chru-lille.fr

$\mathrm{B}$ oth the incidence and the prevalence of atopic dermatitis (AD) have increased significantly in recent decades. More specifically, disease prevalence has been estimated at $4.65 \%$ for France $(1,2)$. As such, this chronic inflammatory skin disease represents an increasing burden to national healthcare systems and to society, through lost workdays and other negative impacts it can have on the daily lives of patients and their families (3-5). Higher rates of anxiety, sleep disorders and depression have been shown to occur in adults with AD compared with those without (6-9). A study of the emotional consequences of the disease concluded that more than half $(57 \%)$ of patients are emotionally burdened (10). Another study concluded that AD causes frequent skin pain, school and/or work absenteeism,

\section{SIGNIFICANCE}

This study found that patients with atopic dermatitis and the dermatologists treating them have both convergent and divergent views regarding various aspects of this disease and its treatment. The differences and similarities reported by participants in this study shed light on the relevance of addressing quality of life aspects during consultations. The results of this study provide several ideas for how dermatologists can contribute to improving patient understanding of, and compliance with, prescribed therapies.

and has a significant effect on sleep (11). One study found that $88 \%$ of persons with severe AD stated that their disease, at least partly, compromised their ability to face life (12).

Thus, in order to address these impacts in close correlation with patient views, it is important to gain a better understanding of the current viewpoints of patients and dermatologists regarding these aspects of the disease. This will enable improvements in patient management, given the broad heterogeneity of $\mathrm{AD}$ in adolescence and adulthood (13). There is a lack of data and publications on the impact of $\mathrm{AD}$ on quality of life, although recent developments $(3,4,14)$ of new treatments for patients with moderate to severe or refractory (15) forms of AD are contributing to an increase in the amount of information being generated in this field.

The objective of this study was to provide a comparative analysis of viewpoints of French dermatologists and patients with $\mathrm{AD}$ that is uncontrolled by topical corticosteroids (TCS), on the impact of $A D$ on various aspects of a patient's life. The study focused on comparing patients' and dermatologists' perceptions of the influence of the symptoms and the chronic nature of this skin disease, as well as the efficacy of available treatments on daily activities. Data were also collected on how AD affected patients' mood, well-being, social, professional, intimate and sexual lives. Secondary objectives included the evaluation of the impact of visible (face and neck areas, hereafter referred to as head and neck AD (HN-AD)) vs non-visible forms of $\mathrm{AD}$, the perception of the different classes of treatments by patients vs dermatologists, and the patient vs dermatologist perceptions of the aetiology of the disease. 


\section{MATERIALS AND METHODS}

This observational cross-sectional study was conducted among 150 dermatologists and 348 adult patients aged $18-85$ years.

\section{Inclusion criteria}

Dermatologists included in this study had to have at least 2 years of experience as a dermatologist and be personally involved in the initiation of $\mathrm{AD}$ treatment. They had to manage at least 20 patients with $\mathrm{AD}$, of which a minimum of 5 patients (for office-based dermatologists) and 10 patients (for hospital and mixed-based practice dermatologists) had to be affected by a form of AD that remained uncontrolled by TCS.

\section{Recruitment and data collection}

Dermatologists were contacted by phone using publicly available data sources for office- and mixed-based practice dermatologists. Hospitals were contacted directly for the recruitment of the hospital-based dermatologists.

The study aimed for a nationwide coverage with no stringent quota for the various French regions.

All patients were recruited through the dermatologists who participated in the study. Dermatologists were instructed to consecutively enrol the next patients they saw in consultation who met the inclusion criteria, i.e. aged 18 years and above, with a form of $\mathrm{AD}$ that remained uncontrolled by TCS, based on their professional knowledge and assessment of the situation. No specific instructions were provided for the definition of "uncontrolled" AD.

Data collection was performed in France between March and July 2017. Both questionnaires used were developed by the authors of this paper. Information was obtained from dermatologists through an in-person interview based on a 6-page questionnaire including 33 questions. Patients provided their responses through a 4-page self-administered questionnaire, with 26 questions. This paper questionnaire was provided to patients by their dermatologist.

The questionnaires were based on closed-ended questions. Two scales were used: a 4-point semantic agreement scale, from "does not at all agree" to "completely agree", along with 10-point scales based on evaluations of treatment satisfaction levels and impact on quality of life variables. For these numerical scales, 1 represented the lowest score ("has no impact or not at all satisfied") and 10 the highest ("has a strong impact, or very satisfied").

\section{Study approach}

Prior to the main data collection, several preparatory steps were put in place to ensure the study feasibility and quality.

Feasibility and sample sizes were defined through preparatory phone interviews with 10 dermatologists who helped to assess the number of patients that could be reasonably included. These 10 interviews were then followed by a qualitative phase, which consisted of 15 exploratory interviews: 9 with dermatologists (3 with each of the 3 different types of practices) and 6 with patients. This step aimed to provide the information required to structure and determine the wording of the final questionnaires that were aimed at retrieving both patients' and dermatologists' perceptions.

The final preparatory step was a pilot session, during which face-to-face interviews were conducted with 5 patients prior to the national roll-out, to check and validate their comprehension of the patient questionnaire.

\section{Sample size}

Based on the sample size of 150 dermatologists, a sample of 348 patients was yielded during the period of recruitment. Group sample sizes of 160 per group (such as for visible vs non-visible forms of $\mathrm{AD}$ ) achieve $85 \%$ power to reject the null hypothesis of equal means when the mean difference in scores is 1 point with a standard deviation (SD) for both groups of 3 points and with a significance level (alpha) 5\% using a 2-sided 2-sample equalvariance $t$-test.

\section{Statistical analysis}

Descriptive data analyses were carried out using Cosi software (Version 4.11, Michel Lorenter Informatique, Bourg en Bresse, France). Results were expressed as mean \pm SD or percentages with $95 \%$ confidence intervals $(95 \% \mathrm{CI})$. Continuous variables were analysed using Student's $t$-test; categorical variables were analysed by means of the $\chi^{2}$ test, with Yates's correction. A 2-sided "alpha" level of $5 \%$ was applied.

To explore the influence of sex and age on the results, multivariate analyses using group characteristics (visible and non-visible forms of $\mathrm{AD}$ ), sex and age using logistic regressions for categorical variables and analysis of covariance for continuous variables were performed.

Table I. Sociodemographic and disease characteristics of the study patient population $(n=348)$

\begin{tabular}{|c|c|}
\hline Socio-demographic and disease characteristics & $n(\%)$ \\
\hline Female & $179(51)$ \\
\hline Male & 169 (49) \\
\hline \multicolumn{2}{|l|}{$\operatorname{Age}^{\mathrm{a}}$} \\
\hline $18-25$ years & $65(19)$ \\
\hline $26-35$ years & $84(24)$ \\
\hline $36-45$ years & $85(25)$ \\
\hline $46-55$ years & $42(12)$ \\
\hline$>55$ years & $67(19)$ \\
\hline \multicolumn{2}{|l|}{ Census division ${ }^{\mathrm{b}}$} \\
\hline North West & $26(8)$ \\
\hline North East & $121(35)$ \\
\hline South West & $40(12)$ \\
\hline South East & $65(19)$ \\
\hline Paris Area & $81(23)$ \\
\hline \multicolumn{2}{|l|}{ Socio-economic level ${ }^{\mathrm{c}}$} \\
\hline A & $84(24)$ \\
\hline $\mathrm{B}$ & $25(8)$ \\
\hline C & $140(40)$ \\
\hline Not active & $99(28)$ \\
\hline \multicolumn{2}{|l|}{ Onset of atopic dermatitis ${ }^{d}$} \\
\hline During childhood & $203(58)$ \\
\hline During adolescence & $75(22)$ \\
\hline During adulthood & $69(20)$ \\
\hline \multicolumn{2}{|l|}{ Current phase $\mathrm{e}^{\mathrm{e}}$} \\
\hline Flare up phase & $197(57)$ \\
\hline Quiet phase & $150(43)$ \\
\hline \multicolumn{2}{|l|}{ Localisation $^{f}$} \\
\hline Externally visible AD: head and neck area & $188(54)$ \\
\hline Externally non-visible AD: other areas & $160(46)$ \\
\hline
\end{tabular}

Patients included in this study were selected by their dermatologists. To be included, they had to be diagnosed with atopic dermatitis (AD) and not well controlled by topical corticosteroids. All above information was provided by patients themselves, by means of a self-administered questionnaire

${ }^{a}$ Age was calculated based on year of birth. ${ }^{b}$ Data collection was based on indication of French department, which where regrouped into 5 major geographical regions. ${ }^{\mathrm{C}}$ Data collection was based on the following categories generally used in market research and opinion polls: Socio-economic level A: Shop owner, Craftsman, Directors (of companies), Self-employed, Manager; Socio-economic level B: Intermediate professions, Technicians; Socio-economic level C: Employees, Workers/Not active: Retired, Not active (housewife or man, unemployed...). ${ }^{d}$ Data on the onset of $A D$ was based on the following question: at which time did this skin issue appear [1 answer]: during childhood, during adolescence, during adulthood. ${ }^{\text {DData on }}$ the active vs the quiet phase of the disease was based on the following question: Based on your current symptoms, would you say that: You are in a flare-up phase, meaning that you have a lot of symptoms; You are in a quiet phase, meaning that you have few symptoms. 'Data on disease localisation was based on the following question: Which part(s) of yourbody is (are) currently affected? [Multiple responses possible] Face/neck; Scalp; Hands; Arms/Legs; Torso; Other part please specify. 
Table II. Percentage of "agree" between dermatologist and patient perceptions concerning emollients and topical corticosteroids

\begin{tabular}{|c|c|c|c|c|}
\hline & $\begin{array}{l}\text { Dermato- } \\
\text { logists }^{\mathrm{a}}\end{array}$ & Patients ${ }^{a}$ & $\begin{array}{l}\text { Difference, \% } \\
{[95 \% \mathrm{CI}]}\end{array}$ & $p$-value ${ }^{\mathrm{b}}$ \\
\hline Emollients, $n$ & 123 & 198 & & \\
\hline Emollients work well, \% & 82 & 57 & $25[15 ; 35]$ & $<0.001$ \\
\hline Topical corticosteroids, $n$ & 147 & 275 & & \\
\hline Topical corticoids (cortisone-based creams or ointments) work well, \% & 98 & 79 & $19[14 ; 24]$ & $<0.001$ \\
\hline Emollients, $n$ & 133 & 311 & & \\
\hline Emollients have no side-effects, \% & 89 & 89 & $0[0 ; 6]$ & 1 \\
\hline Topical corticosteroids, $n$ & 45 & 134 & & \\
\hline Topical corticosteroids have no side-effects, \% & 30 & 38 & $0[0 ; 8]$ & 0.3 \\
\hline Emollients, $n$ & 115 & 176 & & \\
\hline $\begin{array}{l}\text { It is difficult for patients to apply emollients to certain areas of their body / it is difficult for me to apply the } \\
\text { creams to certain areas of my body, \% }\end{array}$ & 77 & 51 & $26[15 ; 37]$ & $<0.001$ \\
\hline Topical corticosteroids, $n$ & 92 & 189 & & \\
\hline $\begin{array}{l}\text { It is difficult for patients to apply corticosteroids to certain areas of their body / it is difficult for me to apply } \\
\text { topical corticosteroids (cortisone-based creams or ointments) to certain areas of my body, \% }\end{array}$ & 61 & 54 & $7[0 ; 19]$ & 0.3 \\
\hline Emollients, $n$ & 63 & 102 & & \\
\hline My patients use them (emollients) as little as possible / I use them (emollients) as little as possible, $\%$ & 42 & 29 & $13[0 ; 28]$ & 0.09 \\
\hline Topical corticosteroids, $n$ & 117 & 218 & & \\
\hline $\begin{array}{l}\text { My patients use them (topical corticosteroids) as little as possible / I use them (topical corticosteroids) as } \\
\text { little as possible, \% }\end{array}$ & 78 & 63 & $15[5 ; 25]$ & 0.005 \\
\hline
\end{tabular}

aTable values are the percentage of sub-totals for "Completely Agree" and "Rather Agree" out of a 4-point Likert scale (completely agree, rather agree, rather disagree, completely disagree). ${ }^{\mathrm{b}} p$-values are calculated by $t$-tests for independent groups.

$95 \%$ CI: $95 \%$ confidence interval.

\section{RESULTS}

\section{Patient population}

The patient population $(n=348)$ for this study included a balanced number of males (49\%) vs females (51\%). A large proportion of patients were in the age range $26-45$ years $(49 \%)$, with a median age of 42 years. All the regions of France were represented. Further details are shown in Table I. Onset of AD was during childhood for a majority (58\%) of patients. For the remainder of the patient population $(42 \%)$, the first signs and symptoms dated back to, more or less equally, their adolescence $(22 \%)$ or adulthood $(20 \%)$. More than half of patients had skin lesions that were visible on their face or neck (54\%). A slightly greater proportion considered that they were in a stage of disease flare-up (57\%).

\section{Dermatologist population}

The dermatologist population $(n=150)$ included $68 \%$ female and $32 \%$ male doctors. The level of experience that dermatologists had in treating $\mathrm{AD}$ was relatively high; $66 \%$ had over 10 years of experience, the remaining $33 \%, 2-10$ years of experience, with a mean of 19 years of experience. Among the 150 dermatologists, 58 were office-based, 58 hospital-based and 34 mixed practice dermatologists.

\section{Level of information on atopic dermatitis}

Of the dermatologist population, $37 \%$ considered their patients to be well informed about their disease, while $76 \%$ of patients claimed they were well informed $(p<0.001)$. A little over half (53\%) of the patients believed that it is important to determine to what one is allergic, in order to treat the disease, and $39 \%$ of patients believed that their $\mathrm{AD}$ had an allergic origin (data not shown).

\section{Treatments for atopic dermatitis}

Treatments for $\mathrm{AD}$ were constraining for $93 \%$ of the dermatologists compared with $76 \%$ of patients. Patients indicated that they spend a mean of 13 min a day, applying topical treatments for AD (e.g. emollients, TCS). Dermatologists estimated the mean application time to be approximately $12 \mathrm{~min}$ per day (data not shown).

\section{Emollients}

Most respondents ( $82 \%$ of dermatologists and $57 \%$ of patients) considered that emollients work well $(p<0.001)$. Regarding side-effects, $89 \%$ of dermatologists and the same proportion of patients agreed that emollients do not have side-effects, with a proportion of, respectively, 57\% and $44 \%$ who "strongly agree" with this claim (Table II).

The majority of dermatologists (63\%) vs a minority of patients (34\%) gave overall satisfaction ratings between 7 and 10 for emollients $(p<0.001)$. Mean satisfaction ratings were 6.7 for dermatologists vs 5.4 for patients $(p<0.001)$ (Table III).

Table III. Dermatologist and patient satisfaction levels with treatments (means and $7-10$ rates)

\begin{tabular}{lllll}
\hline & $\begin{array}{l}\text { Dermato- } \\
\text { logists }^{\mathrm{a}}\end{array}$ & Patients $^{\mathrm{a}}$ & $\begin{array}{l}\text { RR }[95 \% \\
\text { CI] }\end{array}$ & $p$-value \\
\hline Emollients, $n$ & 150 & 331 & & \\
Scale 1-10, mean (SD) & $6.7(2)$ & $5.4(2.3)$ & $0.9[1.7]$ & $<0.001$ \\
Scale 7-10, \% & 63 & 34 & $19.7[38.3]$ & $<0.001$ \\
Topical corticosteroids, $n$ & 150 & 340 & & \\
Scale 1-10, mean (SD) & $7.4(1.5)$ & $6.0(2.1)$ & $1.1[1.7]$ & $<0.001$ \\
Scale 7-10, \% & 76 & 43 & $24.4[41.6]$ & $<0.001$ \\
Systemic immune & 136 & 111 & & \\
$\quad$ suppressants, $n$ & $7.1(1.6)$ & $6.5(2.3)$ & $0.1[1.1]$ & 0.017 \\
Scale 1-10, mean (SD) & 74 & 56 & $6.2[29.8]$ & $<0.001$ \\
Scale 7-10, \% & & &
\end{tabular}

a Table values show mean ratings and percentage of sub-totals for rate between 7-10, out of a scale from 1 to 10 , where 1 means "not at all satisfied" and 10 "completely satisfied". ${ }^{b} p$-values were calculated by $t$-tests for independent groups. SD: standard deviation; 95\% CI: 95\% confidence interval. 
Dermatologists estimated that a mean of $53 \%$ of the patients to whom they prescribe emollients have poor compliance when applying them. Of the patients, $52 \%$ considered that they do not always follow the instructions they receive (for example: premature cessation of treatment or personal decision to decrease the prescribed dosage for this class of products - data not shown) for this class of products (data not shown). Regarding emollients, $42 \%$ of dermatologists believed that patients use them as little as possible, compared with $29 \%$ of patients who stated they use them as little as possible $(p=0.09)$ (Table II).

\section{Topical corticosteroids}

The great majority of dermatologists $(98 \%)$ claimed that TCS work well, compared with $79 \%$ of patients who provided the same answer $(p<0.001)$. Respective mean satisfaction rates for TCS were 7.4 for dermatologists and 6.0 for patients $(p<0.001)$. Similarly, the percentages of dermatologists and patients who provided high (7-10) levels of satisfaction ratings for TCS were, respectively, $76 \%$ and $43 \%(p<0.001)$ (Table III).

Regarding side-effects, a minority (30\% of the dermatologists and $38 \%$ of the patients; $p=0.3$ ) considered that TCS do not have side-effects, yet $78 \%$ of dermatologists and $63 \%$ of patients $(p=0.005)$ claimed that they use them as little as possible (Table II).

Dermatologists estimated that a mean of $44 \%$ of patients have poor compliance regarding TCS, while $61 \%$ of patients indicated that they do not always follow the instructions given by their dermatologists for the usage of TCS. It was reported by $61 \%$ of dermatologists and
$54 \%$ of patients $(p=0.3)$ that it is difficult to apply TCS to certain parts of the body. A total of $39 \%$ of patients reported that they used 1.5 tubes of TCS or more per month, with only one patient out of 5 stating that they used more than 2 tubes per month.

\section{Systemic treatments}

For systemic treatments, mean satisfaction rates did not differ significantly between the 2 survey populations (7.1 for dermatologists and 6.5 for patients, $p=0.017$ ). However, among the populations that provided a high 7-10 satisfaction rating, differences were more important. Significantly fewer patients $(56 \%)$ than dermatologists $(74 \%)$ indicated a satisfaction level of $7-10$ for this class $(p<0.001)$ (Table III).

\section{Impact of atopic dermatitis on quality on life}

For the entire patient population studied, the overall impact of $\mathrm{AD}$ on quality-of-life obtained a mean rating of 6.6. A slight majority of patients (58\%) stated a strong overall impact, by providing a rating between 7 and 10 .

Taken individually, the various quality of life dimensions showed mean impact ratings that ranged from 5.6 for the disease impact on daily activities, mood and psychological state, to $4.3(p<0.001)$, for its impact on family life (Table IV).

Among the 348 patients, 54\% $(n=188)$ stated that they had HN-AD. Differences in mean ratings between the HN-AD population and the population with lesions on other body localisations ranged between 0.6 (disease

Table IV. Patient perceptions of atopic dermatitis (AD) impact on different quality of life dimensions, by localisation

\begin{tabular}{|c|c|c|c|c|c|c|}
\hline & $\begin{array}{l}\text { Total patients } \\
n=348\end{array}$ & $\begin{array}{l}\text { Visible AD (face } \\
\text { and neck) } \\
n=188\end{array}$ & $\begin{array}{l}\text { Non-visible AD (other } \\
\text { parts of the body) } \\
n=160\end{array}$ & $\begin{array}{l}\text { Mean or \% } \\
\text { difference } \\
{[95 \% \mathrm{CI}]}\end{array}$ & $\begin{array}{l}\text { Univariate } \\
p \text {-value }{ }^{\mathrm{b}}\end{array}$ & $\begin{array}{l}\text { Multivariate } \\
p \text {-value }\end{array}$ \\
\hline \multicolumn{7}{|l|}{ Overall, $n$} \\
\hline Scale $1-10$, mean (SD) & $6.6(4.9)$ & $7.0(1.9)$ & $6.2(1.8)$ & $0.8[0.4 ; 1.2]$ & $<0.01$ & $<0.01$ \\
\hline Rate $7-10, \%$ & 58 & 64 & 51 & $13[3 ; 23]$ & 0.03 & 0.03 \\
\hline \multicolumn{7}{|l|}{ Impact on daily activities, $n$} \\
\hline Scale $1-10$, mean (SD) & $5.6(2.4)$ & $5.9(2.3)$ & $5.3(2.4)$ & $0.6[0.1 ; 1.1]$ & 0.01 & 0.02 \\
\hline Rate $7-10, \%$ & 42 & 46 & 37 & $9[0 ; 18]$ & 0.12 & 0.12 \\
\hline \multicolumn{7}{|l|}{ Impact on professional life, $n$} \\
\hline Scale $1-10$, mean (SD) & $5.3(2.9)$ & $5.7(2.8)$ & $4.9(2.9)$ & $0.8[0.2 ; 1.4]$ & 0.01 & 0.02 \\
\hline Rate $7-10, \%$ & 42 & 47 & 36 & $9[0 ; 19]$ & 0.047 & 0.07 \\
\hline \multicolumn{7}{|c|}{ Impact on mood and psychological state, $n$} \\
\hline Scale $1-10$, mean (SD) & $5.6(2.4)$ & $6.0(2.3)$ & $5.1(2.4)$ & $0.9[0.4 ; 1.4]$ & $<0.001$ & $<0.001$ \\
\hline Rate $7-10, \%$ & 36 & 41 & 31 & $10[1 ; 21]$ & 0.04 & 0.03 \\
\hline \multicolumn{7}{|l|}{ Impact on love life and life as a couple, $n$} \\
\hline Scale $1-10$, mean (SD) & $5.1(2.8)$ & $5.6(2.8)$ & $4.6(2.8)$ & $1.0[0.4 ; 1.6]$ & 0.001 & $<0.01$ \\
\hline Rate $7-10, \%$ & 38 & 46 & 29 & $17[7 ; 27]$ & 0.002 & 0.002 \\
\hline \multicolumn{7}{|l|}{ Impact on intimate and sexual life, $n$} \\
\hline Scale $1-10$, mean (SD) & $4.8(3.0)$ & $5.3(3.0)$ & $4.3(3.0)$ & $1.0[0.4 ; 1.6]$ & 0.002 & 0.003 \\
\hline Rate $7-10, \%$ & 38 & 45 & 30 & $15[5 ; 25]$ & 0.005 & 0.005 \\
\hline Impact on social life and going out, $n$ & 348 & 188 & 160 & & & \\
\hline Scale $1-10$, mean (SD) & $5.0(2.5)$ & $5.5(2.4)$ & $4.4(2.4)$ & $1.1[0.6 ; 1.6]$ & $<0.001$ & $<0.0001$ \\
\hline Rate $7-10, \%$ & 32 & 38 & 26 & $12[2 ; 22]$ & 0.02 & 0.02 \\
\hline Impact on family life, $n$ & 348 & 188 & 160 & & & \\
\hline Scale $1-10$, mean (SD) & $4.3(2.6)$ & $4.8(2.7)$ & $3.8(2.4)$ & $1.0[0.5 ; 1.5]$ & $<0.001$ & $<0.001$ \\
\hline Rate $7-10, \%$ & 22 & 29 & 14 & $13[3 ; 23]$ & 0.002 & 0.002 \\
\hline
\end{tabular}

On a scale from 1 to $10: 1$ meaning "does not affect at all" and 10 "strongly affects".

${ }^{a}$ For this table, the 2 samples which were compared were "Visible $A D^{\prime \prime}$ and "Non-visible AD". " $p$-values were calculated by $t$-tests or $x^{2}$ tests for independent groups. ${ }^{c} p$-values were calculated by analysis of covariance or logistic regression adjusted on age and sex.

SD: standard deviation; $95 \%$ CI: $95 \%$ confidence interval. 
impact on daily activities with a mean of 5.9 for HN-AD vs 5.3 for other forms $(p=0.01)$ ) and 1.1 (impact of the disease on social life and going out, with a mean of 5.5 for HN-AD vs 4.4 for other forms $(p<0.001)$ ) (Table IV).

Further analysis showed that the highest impact rating of $7-10$ for overall impact, involved $64 \%$ of patients with visible $\mathrm{HN}-\mathrm{AD}$, compared with $51 \%$ of patients whose disease affects other parts of their body $(p=0.03)$ (Table IV). The 2 quality of life dimensions for which the difference in perception of impact of disease between patients and dermatologists were most significant were: impact on love life and life as a couple (17 percentage points difference), along with the impact on intimate and sexual life (15 percentage points difference).

No sex or age effects were observed in the results, and the differences between the HN-AD population and the population with lesions on other localisations are consistent using the multivariate models.

Further details of patients' perceptions of the impact of disease on quality of life are shown in Table IV.

\section{DISCUSSION}

\section{Study strengths}

A strength of this study is that it gathered insights from the 3 different types of dermatology practices that exist in France: office-, hospital- and mixed-based practice dermatologists. The patient population for this study is robust and reflects the different types of French patients, across age groups and socio-economic categories, who require treatment for $\mathrm{AD}$.

\section{Study limitations}

All patients were recruited by participating dermatologists who independently identified, within their practice, adults whose AD remained symptomatic despite being treated with TCS. The study did not define severity or other recruitment criteria related to severity prior to developing the questionnaires. All questionnaires were validated by the scientific committee.

Another limitation is that the study was not designed as a clinical study. Patient refusal to participate in the study was not documented. Thus there was no information on either the number of dropouts or the reasons.

Another bias exists relative to the inclusion criteria targeting patients who were not controlled by TCS. This bias prevents the study from being representative of the AD population, which also includes patients who are adequately managed by TCS. Thus, this study does not enable us to draw any conclusions regarding differences between these 2 types of patients. The main reason for the exclusion criteria was to gain insights on convergences and divergences between patients and physicians in a setting where patients still have AD. A key element to note here, however, is that physicians were not given any exclusion criteria and were allowed to provide responses to the questionnaire based on their interactions with their entire patient population.

Although some quality of life dimensions are covered, this study cannot be considered as a quality of life study. Its originality lies in the mirror approach, for which dermatologists and patients responded to similar questions, in order to evaluate the differences in perception. Current validated quality of life measures are hardly compatible with the "mirror" approach, as they would have added significantly to the length and complexity of the questionnaire for patients, and thus would have compromised the feasibility of the study.

\section{Convergence and divergence}

This study showed that patients with $\mathrm{AD}$ and the dermatologists who were treating them had both convergent and divergent viewpoints about various aspects of this disease and its treatment. For example, while most of the patients stated that they were well informed about $\mathrm{AD}$, most of their dermatologists considered that this was not the case. Indeed, dermatologists often consider that their patients have persistent misconceptions about the alleged allergic origin of $\mathrm{AD}$. There were overall more divergent than convergent viewpoints, thereby confirming the need for greater dialogue during clinical practice and lack of effective treatments for concerned patients.

Significant differences were also found in how patients and dermatologists evaluated the efficacy of available treatments, including emollients, TCS, immune suppressants, antihistamines, other medicines, phototherapy, as well as other non-medical treatment methods. Patient evaluations of their treatments were consistently lower than those of their dermatologists. These findings need to take into consideration the selection bias linked to the fact that only patients who remained uncontrolled by TCS were included. In addition, new biotechnology options had not yet been launched at the time of the study. Furthermore, it should be noted that both patients and doctors indicated a lack of patient compliance with TCS.

Overall, dermatologists showed an empathetic attitude towards patients, acknowledging the importance of the impact of $\mathrm{AD}$ on different dimensions of patients' lives. The exception was professional life, for which dermatologists tended to underestimate the impact of AD.

This particular finding was confirmed by the large $(n=1,024)$ French Eczema Cohorte Longitudinale Adultes (ECLA) study, the first study to use the ABS-A (Atopy Burden Score - Adult) tool to evaluate the burden of AD (16). In the ECLA study, disease burden and impact on quality of life was greater for patients with severe AD $(p<0.0001)$ compared with patients with mild to moderate $\mathrm{AD}$. For these patients, their $\mathrm{AD}$ had a negative impact on their professional activity, number and duration of absences from work and on their productivity (17). 
Concerning sexual life, the findings of the current study are in line with the ECLA study, which also demonstrated a high impact of AD on sexual health, because of its relatively frequent presence on the genitals and other visible areas of the body (13).

The current results regarding disease topography clearly indicate that head and neck localisation is a major issue that needs to be taken into consideration to optimize disease management, as disease impact scores were higher across the board for head and neck patients. External visibility of the disease not only stigmatizes patients, but can also prevent them from pursuing their professional aspirations, and appears to be somewhat underestimated by dermatologists in terms of its impact on quality of life dimensions.

New trends in patient care encourage the examination of what occurs outside of the doctor's office as well as the patient journey. It is becoming increasingly important to take into consideration the impact of a prescribed therapeutic option on a patient's daily life. In fact, healthrelated quality of life has become a major parameter in dermatology, especially for the management of chronic diseases, such as $\mathrm{AD}$, with guidelines and consensus documents now recommending the use of patientrelevant outcomes to be measured in clinical trials (18).

There is currently no simple scale or consensus for simultaneously evaluating both $\mathrm{AD}$ severity and burden. Scoring methods generally used in Europe, in trials such as SCORing Atopic Dermatitis (SCORAD) and Eczema Area and Severity Index (EASI) to measure AD-severity or Dermatology Life Quality Index (DLQI) do not evaluate the burden of AD. Furthermore, these scales are not widely used in daily practice. In the current study, 30\% of dermatologists stated that they never use the DLQI, and $21 \%$ state that they use it only rarely.

Since consistently more than two-thirds of patients in the current study reported a strong impact of $\mathrm{AD}$ on all quality of life dimensions investigated, it is necessary to better address these issues in clinical practice. This is particularly important for patients with the more visible head and neck forms of AD. By pointing out specific areas in which patients and dermatologists have convergent and divergent viewpoints, the current study results can help to improve patient understanding and compliance to prescribed therapies on the one hand and, on the other, contribute to dermatologists' selection of treatment options to better reduce the negative impact of $\mathrm{AD}$ on patients' quality of life.

\section{ACKNOWLEDGEMENTS}

Sanofi provided financial support for this study.

Conflicts of interest: AS is a consultant for Novartis and Sanofi, an investigator for Novartis and a speaker for Novartis and Sanofi. CT is a Sanofi employee and may hold shares and/or stock options in the company. $\mathrm{CB}$ is head of the healthcare department at Ifop, a market research agency that conducts studies on behalf of different companies in the life science sector, including Sanofi. DS-S is an investigator for Astra-Zeneca, Abbvie, Boehringer, Celgene, Leo Pharma, Lilly, Novartis and Regeneron-Sanofi, a consultant for Abbvie, Astra-Zeneca, Janssen, Lilly, Novartis, Pfizer and Sanofi and a speaker for AbbVie, Janssen, Eli Lilly, Novartis, Pfizer and Sanofi.

\section{REFERENCES}

1. Richard MA, Corgibet F, Beylot-Barry M, Barbaud A, Bodemer C, Chaussade V, et al. Sex- and age-adjusted prevalence estimates of five chronic inflammatory skin diseases in France: results of the "OBJECTIFS PEAU" study. J Eur Acad Dermatol Venereol 2018; 32: 1967-1971.

2. Barbarot S, Auziere S, Dadkari A, Girolomoni G, Puig L, Simpson EL. Epidemiology of atopic dermatitis in adults: results from an international survey. Allergy 2018; 73: 1284-1293.

3. Drucker AM. Atopic dermatitis: burden of illness, quality of life, and associated complications. Allergy Asthma Proc 2017; 38: 3-8.

4. Drucker AM, Wang AR, Li W-Q, Sevetson E, Block JK, Qureshi AA. The burden of atopic dermatitis: summary of a report for the National Eczema Association. J Invest Dermatol 2017; 137: 26-30.

5. Adamson AS. The economics burden of atopic dermatitis. Adv Exp Med Biol 2017; 1027: 79-92.

6. Silverberg JI, Gelfand JM, Margolis DJ, Boguniewicz M, Fonacier L, Grayson MH, et al. Symptoms and diagnosis of anxiety and depression in atopic dermatitis in U.S. adults. Br J Dermatol 2019; 181: 554-565.

7. Patel KR, Immaneni S, Singam V, Rastogi S, Silverberg JI Association between atopic dermatitis, depression, and suicidal ideation: a systematic review and meta-analysis, J Am Acad Dermatol 2019; 80: 402-410.

8. Eckert L, Gupta S, Gadkari A, Mahajan P, Gelfand JM. Burden of illness in adults with atopic dermatitis (AD): analysis of National Health and Wellness Survey data from France, Germany, Italy, Spain and the UK. J Am Acad Dermatol 2019; 81: 187-195.

9. Bender BG, Ballard R, Canono B, Murphy JR, Leung DYM. Disease severity, scratching, and sleep quality in patients with atopic dermatitis. J Am Acad Dermatol 2008; 58: 415-420.

10. Arents BWM, Mensing $U$, Seitz IA, Wettemann, Fink-Wagner $\mathrm{AH}$, de Carlo G, Zink A, et al, Atopic eczema score of emotional consequences - a questionnaire to assess emotional consequences of atopic eczema, Allergo J Int 2019; 28: 277-288.

11. Reed B, Blaiss MS. The burden of atopic dermatitis. Allergy Asthma Proc 2018; 39: 406-410.

12. Ring J, Zink A, Arents BWM, Seitz IA, Mensing U, Schielein MC, Wettemann N, et al. Atopic eczema: burden of disease and individual suffering - results from a large EU study in adults, J Eur Acad Dermatol Venereol 2019; 33: 1331-1340.

13. Garmhausen D, Hagemann T, Bieber T, Dimitriou I, Fimmers R, Diepgen T, Novak N. Characterization of different courses of atopic dermatitis in adolescent and adult patients. Allergy 2013; 68: 498-506.

14. Nutten S. Atopic dermatitis: global epidemiology and risk factors. Ann Nutr Metab 2015; 66: 8-16.

15. Deleanu D, Nedelea I. Biological therapies for atopic dermatitis: an update. Exp Ther Med 2019; 17: 1061-1067.

16. Misery L, Seneschal J, Reguiai Z, Reguiai Z, Merhand S, Héas $S$, et al. Patient burden is associated with alterations in quality of life in adult patients with atopic dermatitis: results from the ECLA Study. Acta Derm Venereol 2018; 98: 713-714.

17. Misery L, Seneschal J, Reguiai Z, Merhand S, Héas S, Huet $F$, et al. The impact of atopic dermatitis on sexual health. J Eur Acad Dermatol Venereol 2019; 33: 428-432.

18. Langenbruch A, Radtke MA, Gutknecht M, Augustin M. Does the Dermatology Life Quality Index (DLQI) underestimate the disease-specific burden of psoriasis patients? J Eur Acad Dermatol Venereol 2019; 33: 123-127. 